\title{
How equitable are community health worker programmes and which programme features influence equity of community health worker services? A systematic review
}

Rosalind McCollum*, Woedem Gomez, Sally Theobald and Miriam Taegtmeyer

\begin{abstract}
Background: Community health workers (CHWs) are uniquely placed to link communities with the health system, playing a role in improving the reach of health systems and bringing health services closer to hard-to-reach and marginalised groups. A systematic review was conducted to determine the extent of equity of CHW programmes and to identify intervention design factors which influence equity of health outcomes.

Methods: In accordance with our published protocol, we systematically searched eight databases from 2004 to 2014 for quantitative and qualitative studies which assessed access, utilisation, quality or community empowerment following introduction of a CHW programme according to equity stratifiers (place of residence, gender, socio-economic position and disability). Thirty four papers met inclusion criteria. A thematic framework was applied and data extracted and managed, prior to charting and thematic analysis.

Results: To our knowledge this is the first systematic review that describes the extent of equity within CHW programmes and identifies CHW intervention design features which influence equity. CHW programmes were found to promote equity of access and utilisation for community health by reducing inequities relating to place of residence, gender, education and socio-economic position. CHWs can also contribute towards more equitable uptake of referrals at health facility level. There was no clear evidence for equitable quality of services provided by CHWs and limited information regarding the role of the CHW in generating community empowerment to respond to social determinants of health. Factors promoting greater equity of $\mathrm{CHW}$ services include recruitment of most poor community members as CHWs, close proximity of services to households, pre-existing social relationship with $\mathrm{CHW}$, provision of home-based services, free service delivery, targeting of poor households, strengthened referral to facility, sensitisation and mobilisation of community. However, if CHW programmes are not well planned some of the barriers faced by clients at health facility level can replicate at community level.

Conclusions: $\mathrm{CHWs}$ promote equitable access to health promotion, disease prevention and use of curative services at household level. However, care must be taken by policymakers and implementers to take into account factors which can influence the equity of services during planning and implementation of CHW programmes.
\end{abstract}

Keywords: Equity, Inequity, Community health worker, Close-to-community provider, Systematic review

\footnotetext{
* Correspondence: r.mccollum@liverpool.ac.uk; rosalindmccollum@gmail.com
}

Liverpool School of Tropical Medicine, Pembroke Place, Liverpool L3 5QA, UK 


\section{Background}

There have been substantial global reductions in child and maternal mortality over the past two decades [1]. However, dramatic differences in mortality and life expectancy exist between and within countries [2,3]. Evidence has consistently shown that disadvantaged groups have poorer survival chances [2, 4] and lower use of facility-based services [5]. As the World Health Organization 'Closing the Gap in a Generation' report (2008) describes 'gender, education, occupation, income, ethnicity and place of residence are all closely linked to people's access to, experiences of, and benefits from health care' (page 8 [2]).

Global interest and investment in community health services has been building to address these gaps and as a pathway to Universal Health Coverage (UHC), with substantial commitment to Community Health Worker (CHW) programmes (see key definitions) in resourceconstrained health systems [7-9]. Work of CHWs has been shown to improve equitable child survival, health and nutrition $[1,10]$ by bringing services closer to the homes of hard-to-reach and underserved populations [6, $11,12]$. The effectiveness of using CHWs to promote immunisation and initiation of breastfeeding and to reduce maternal and child morbidity and mortality, compared with usual care has been demonstrated [13]. However, new health interventions typically reach those with higher socio-economic position first, only benefiting the poor later, in what is known as the 'inverse equity hypothesis' [14] and so introducing CHWs within a health system should not be assumed to automatically result in equitable coverage of health services [15]. A wide range of intervention design factors that may be inequitably applied influence CHW performance, such as a mix of incentives, frequent supervision, continuous training, community involvement and strong coordination between $\mathrm{CHWs}$ and health workers $[11,16]$. Community, economic, sociocultural factors and education status of the target group (among other factors) have also been demonstrated to influence CHW performance and service coverage [17]. There is a need to better understand the design and contextual factors of CHW programmes which impact health equity within populations.

We conducted a systematic review that followed the Preferred Reporting Items for Systematic Reviews and Meta-Analysis Equity (PRISMA-E) guidelines as these were specifically designed to help reviewers identify, extract, and synthesise evidence on equity in systematic reviews [18]. We set out to respond to two research questions:

1. What evidence is there of (in)equity in $\mathrm{CHW}$ programmes?

2. What influences how equitable CHW programmes are in terms of access, utilisation, quality and community empowerment?

\section{Methods}

In this section we summarise the development of guiding conceptual framework, key definitions, search strategy development, selection criteria, data quality assessment, data extraction and data synthesis and analysis.

\section{Conceptual framework}

We developed a conceptual framework (Fig. 1) derived from three complementary pieces of work:

1. An initial reading of the literature relating to equity and service provision $[2,4,19-23]$ led to the identification of the importance of policy and context in influencing social position which in turn influences the four key outcomes-access, utilisation, quality and community empowerment.

2. An adaptation of the PROGRESS plus ${ }^{1}$ framework developed for ensuring explicit consideration of equity in systematic reviews and new intervention studies [24] led to the inclusion of equity stratifiers defined by social position.

3. Our own previous research $[17,25]$ revealed the importance of social determinants and the interface role played by CHWs between the communities they live within and their health system.

\section{Key Definitions}

CHW: Any health worker carrying out functions related to health care delivery; trained in some way in the context of the intervention, and having no formal professional or paraprofessional certificate or degree in tertiary education (page 7 [13]).

Equitable CHW programme: CHW services contribute towards eliminating unnecessary and avoidable differences in health, where the whole population has equal access to CHW services with appropriate uptake of referral to health facility according to need, utilisation of CHW services according to need and equal quality of CHW services for all [4] contributing towards community empowerment to tackle underlying social determinants of health, so that everyone can attain their full health potential.

Access to CHW services: The delivery of community health services in a timely manner within the client's home or community, including coverage of services.

Utilisation of CHW services: The acceptance and use of community health services provided by CHW either within the home or a local village health post.

Uptake of referral: The acceptance and use of services provided at a health facility following referral by a CHW.

Quality of CHW services: The delivery of community health services by a CHW which adhere to an evidence base resulting in improved health outcomes in an efficient manner, with optimal safety for clients and which take into account client preferences and aspirations [64].

Community empowerment: Both individuals and communities are involved in active participation in community health activities by building capacity and confidence in order to address and tackle power and control over their lives [69]. 


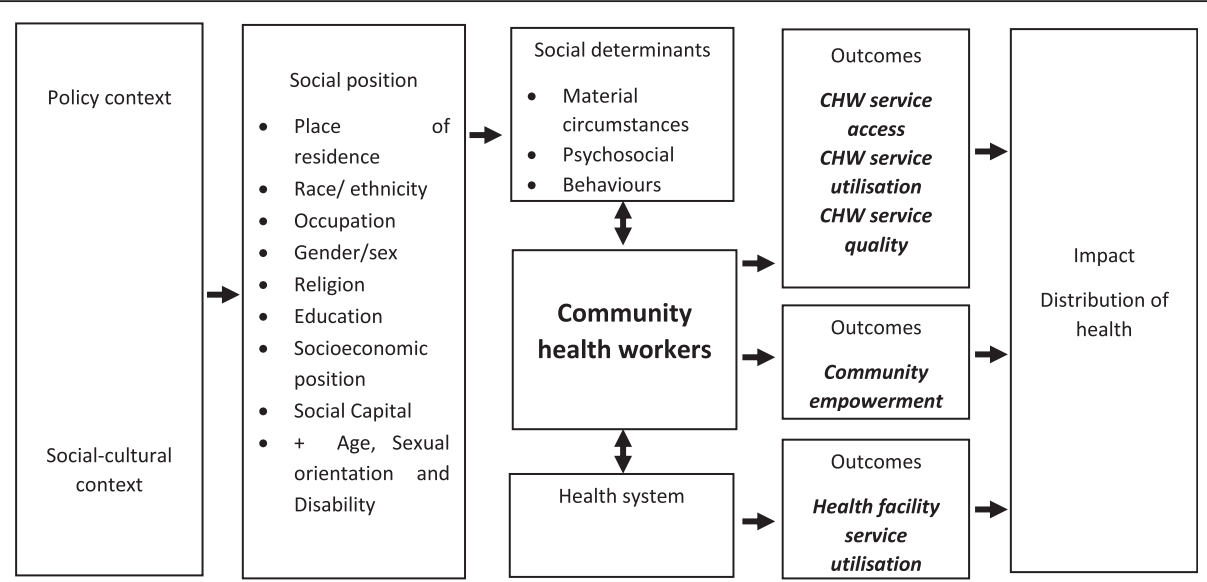

Fig. 1 Conceptual framework for factors influencing equity of services provided by community health workers (CHWs). Outcomes in italics, indicate key areas of investigation for this review

\section{Definitions and search strategy}

In accordance with our published protocol [26] we systematically searched Cochrane Central Register of Controlled Trials (CENTRAL), PUBMED, SCOPUS, Science Direct, Global Health, Social Science Citation Index, CINAHL (for published studies) and POPLINE (for grey literature) to identify suitable studies for inclusion.

Search terms to identify relevant studies included CHW terms, health equity terms (including specific search for terms relating to socioeconomic position, gender, disability and place of residence) and the outcome terms access, utilisation, quality and community empowerment, according to our conceptual framework. ${ }^{2}$

Delimiters were English language and studies published between January 2004 to April 2014, in order to capture the most recent findings working within the time and resources available. The search strategy was developed for use with PUBMED (see Additional file 1), translated and modified for use in the other databases, using controlled vocabulary as appropriate. Reference lists of included papers were searched for potential relevant papers.

\section{Selection Criteria}

Studies were selected for inclusion based on "fitness for purpose" rather than following a hierarchy of evidence, as recommended for equity related reviews [2, 18, 27]. This involved reviewing all relevant articles which met inclusion criteria. Both quantitative and qualitative studies and conference abstracts were selected based on their study objectives and were not excluded based on study methodology.

Inclusion criteria ${ }^{3}$ were: studies which provided an analysis of CHW programme outcome (access, utilisation, quality, empowerment); studies which adopted a universal approach to community health i.e. services provided for an entire population ${ }^{4}$ [28]; studies from high, middle or low income country; any study where CHW programme was conducted at primary/ community level. Exclusion criteria: study published before 2004; non-English language; narratives; opinion pieces or commentaries.

\section{Data extraction and quality assessment}

A coding framework was adapted from the data extraction form used by Kok et al. [11] to reflect the conceptual framework, piloted prior to use and modified through an iterative process following familiarisation with the data. The framework (Additional file 2) was applied and data coded for extraction using NVivo version 10 software. Quality was assessed by applying a modified version of the Critical Appraisal Skills Programme (CASP) quality assessment checklist (Additional file 3) [29].

\section{Data synthesis}

Thematic narrative analysis was used adopting an iterative approach to identify and synthesise concepts found in the studies as a result of the heterogeneity of interventions and outcomes [30]. Narratives were developed and data charted based upon themes arising within the data. Findings for each outcome (access, utilisation, quality, empowerment) and its equity stratifiers were identified as follows:

- Pro-equity = improvement in outcome for vulnerable groups (vulnerable groups based upon PROGRESS plus criteria) compared with the general population / no difference in the outcome between vulnerable groups and the rest of the population

- Anti-equity = vulnerable groups have lower/ deteriorating outcomes compared with general population as a consequence of the $\mathrm{CHW}$ programme 
- Mixed equity = some improvement in an outcome for a vulnerable group but inequities still persist.

These were summarised and charted to provide an insight into the extent of (in)equity. Findings for utilisation were divided into two main aspects: 1) Acceptance and use of community health services provided by $\mathrm{CHW}$ either within the home or at a local village health post or 2) Uptake of referrals made by a CHW to services provided at a health facility. Comparisons were carried out capturing study context and $\mathrm{CHW}$ programme design features exploring similarities and differences in explaining the findings [16].

RM reviewed titles and abstracts to assess eligibility for inclusion. RM assessed full texts against inclusion criteria by completion of an inclusion criteria checklist. WG assessed all full texts selected for inclusion plus $10 \%$ of remaining full text articles using the inclusion criteria checklist. RM coded and extracted data and assessed quality. WG reviewed data extraction providing additional inputs if and when required and assessed quality. Any differences between reviewers were resolved through discussion. Persisting disagreements were resolved by seeking a third reviewer's opinion (MT).

\section{Results}

\section{What evidence is there of (in)equity in CHW programmes?}

Overall, we found that despite extensive studies (4945 titles) and after reading 328 full text papers there were limited studies which assess the level of equity of $\mathrm{CHW}$ programmes (34 papers included, from 32 studies (Fig. 2 and Table 1)). In total 29 papers were quantitative and five were mixed method papers. Of the papers included (see Table 1) 11 provided an equity analysis of the accessibility of services, 29 of the utilisation of services (26 for utilisation of $\mathrm{CHW}$ services provided within the community and six for uptake of referral by $\mathrm{CHW}$ to health facility services), five an analysis of the quality of services and five for community empowerment. Papers were identified as low (5), medium (11) or high (18) quality using the CASP checklist, see Table 1 for quality assessment and study designs.

There was a notable difference in the content of intervention packages between continents. Papers from the Americas (3) presented findings from comprehensive family health programmes; papers from Asia (10) focused on a particular population group, for example maternal and newborn health and papers from Africa (21) tended to have a more disease specific focus, such as malaria or HIV. This difference in the comprehensiveness of CHW programmes in itself raises equity questions, particularly within the African context.

Our findings reveal that $\mathrm{CHW}$ interventions adopting a universal approach can result in improved equity for CHW service access and use (see Table 1 and Additional file 4: Tables S2-S4). CHW services were found to reduce inequities relating to access for place of residence and socio-economic position.

Acceptance and use of community health services provided by CHWs either within the home or local village health post was reported in 26 studies (Additional file 4: Table S3). In some studies CHW services reduced inequities according to place of residence, gender, education, socio-economic position, age, religion, occupation and marital status for community level services. $\mathrm{CHW}$ programmes also have the potential to contribute to more equitable uptake of referrals for health facility services by reducing barriers due to socio-economic position, language and risk identified through six studies (Additional file 4: Table S4).

Quality was less frequently described despite being an important dimension of equity, with only five studies

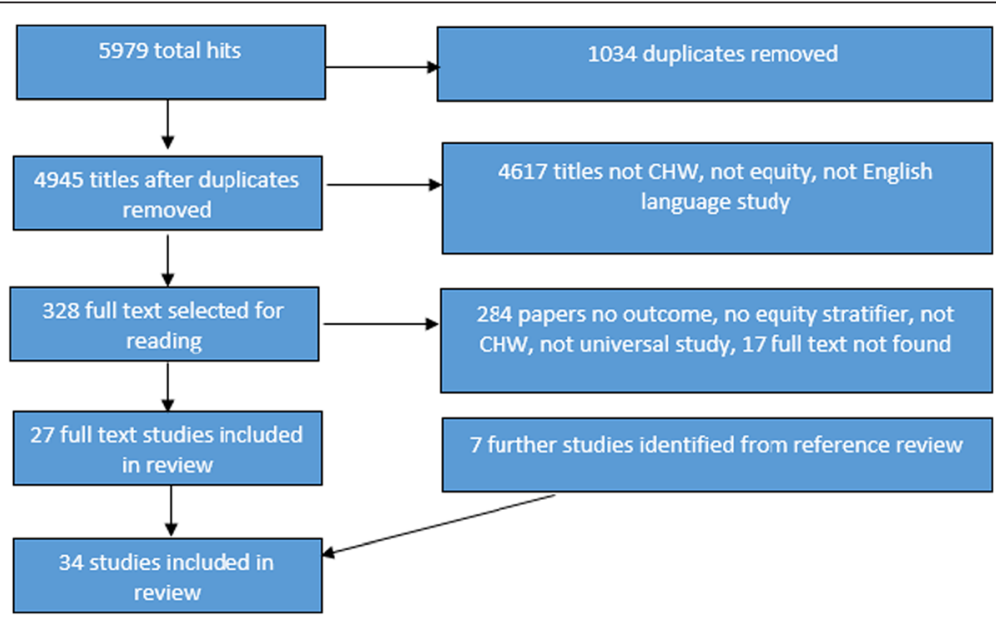

Fig. 2 PRISMA Flow chart search results 
Table 1 summarising country, type of CHW and service provided for included studies

\begin{tabular}{|c|c|c|c|c|}
\hline Article and Country & Type of CHW & CHW intervention & $\begin{array}{l}\text { Study design and } \\
\text { overall quality }\end{array}$ & Equity Stratifier \\
\hline (Atkinson \& Haran, 2005); Brazil & $\begin{array}{l}\text { Community Health } \\
\text { Worker }\end{array}$ & $\begin{array}{l}\text { Comprehensive family health } \\
\text { programme, including CHW } \\
\text { component (not well } \\
\text { explained) }\end{array}$ & $\begin{array}{l}\text { Cross-sectional } \\
\text { household survey; High }\end{array}$ & Quality - Place of residence - \\
\hline \multirow[t]{3}{*}{ (Baqui et al., 2009); Bangladesh } & \multirow{3}{*}{$\begin{array}{l}\text { Community Health } \\
\text { Worker }\end{array}$} & \multirow{3}{*}{$\begin{array}{l}\text { Maternal and Neonatal health } \\
\text { programme with CHW } \\
\text { treatment for neonatal } \\
\text { infections in intervention areas }\end{array}$} & \multirow{3}{*}{$\begin{array}{l}\text { Cluster randomised } \\
\text { controlled trial; High }\end{array}$} & Access - Socio-economic status (SES) + \\
\hline & & & & Utilisation - SES + \\
\hline & & & & Utilisation - Education + \\
\hline (Baqui et al., 2008); India & $\begin{array}{l}\text { Community Health } \\
\text { Worker }\end{array}$ & $\begin{array}{l}\text { NGO facilitation of } \\
\text { government Maternal and } \\
\text { child health programme }\end{array}$ & $\begin{array}{l}\text { Controlled before and } \\
\text { after study; High }\end{array}$ & Empowerment - SES + \\
\hline \multirow{7}{*}{$\begin{array}{l}\text { (Bell, Go, Miguel, Parks, \& Bryan, } \\
\text { 2005); Philippines }\end{array}$} & \multirow{7}{*}{$\begin{array}{l}\text { Village health } \\
\text { worker }\end{array}$} & \multirow{7}{*}{$\begin{array}{l}\text { Malaria control and case } \\
\text { management, community } \\
\text { education and bednet } \\
\text { distribution }\end{array}$} & \multirow{7}{*}{$\begin{array}{l}\text { Cross-sectional } \\
\text { household survey } \\
\text { (including villages with } \\
\text { and without resident } \\
\text { VHW); Medium }\end{array}$} & Access - Place of residence - \\
\hline & & & & Access - Education - \\
\hline & & & & Access - SES- \\
\hline & & & & Utilisation - Place of residence - \\
\hline & & & & Utilisation - Gender + \\
\hline & & & & Utilisation - Education + \\
\hline & & & & Utilisation - Social capital - \\
\hline \multirow{3}{*}{$\begin{array}{l}\text { (Callaghan-Koru et al., 2013); } \\
\text { Malawi }\end{array}$} & \multirow{3}{*}{$\begin{array}{l}\text { Health Surveillance } \\
\text { Assistant }\end{array}$} & \multirow{3}{*}{$\begin{array}{l}\text { Maternal and newborn health } \\
\text { programme, including } \\
\text { antenatal and postnatal home } \\
\text { visits by HSA }\end{array}$} & \multirow{3}{*}{$\begin{array}{l}\text { Before and after study, } \\
\text { with no comparison; } \\
\text { High }\end{array}$} & Access - SES - \\
\hline & & & & Utilisation - SES ? \\
\hline & & & & Empowerment - SES + \\
\hline \multirow[t]{3}{*}{ (Dalal et al., 2013) Kenya } & \multirow[t]{3}{*}{ Counsellor } & \multirow{3}{*}{$\begin{array}{l}\text { Home Based Testing and } \\
\text { Counselling Programme }\end{array}$} & \multirow{3}{*}{$\begin{array}{l}\text { Longitudinal study; } \\
\text { Medium }\end{array}$} & Utilisation - Gender - \\
\hline & & & & Utilisation - Age + \\
\hline & & & & Utilisation - Place of residence - \\
\hline \multirow{3}{*}{$\begin{array}{l}\text { (DasGupta, Mansuri, Nistha, \& } \\
\text { Vishwanath, 2007) Pakistan }\end{array}$} & \multirow[t]{3}{*}{ Lady health worker } & \multirow{3}{*}{$\begin{array}{l}\text { Maternal and neonatal health } \\
\text { programme offering health } \\
\text { and family planning services }\end{array}$} & \multirow{3}{*}{$\begin{array}{l}\text { Cross-sectional study } \\
\text { (used data from Pakistan } \\
\text { Integrated Household } \\
\text { Survey); Low }\end{array}$} & Access - Education - \\
\hline & & & & Utilisation - Gender + \\
\hline & & & & Utilisation - Education + \\
\hline \multirow{12}{*}{$\begin{array}{l}\text { (Fort, Grembowski, Heagerty, } \\
\text { Lim, \& Mercer, 2012) Guatemala }\end{array}$} & \multirow{12}{*}{$\begin{array}{l}\text { Community Nurse } \\
\text { Auxilliary }\end{array}$} & \multirow{12}{*}{$\begin{array}{l}\text { Comprehensive family health } \\
\text { programme }\end{array}$} & \multirow{12}{*}{$\begin{array}{l}\text { Longitudinal prospective } \\
\text { cohort; Medium }\end{array}$} & Utilisation - Language + \\
\hline & & & & Utilisation- Education? \\
\hline & & & & Utilisation - Place of residence - \\
\hline & & & & Utilisation - risk + \\
\hline & & & & Utilisation - SES + \\
\hline & & & & Utilisation - Age \\
\hline & & & & Utilisation - Religion - \\
\hline & & & & Utilisation - Family type - \\
\hline & & & & Utilisation - Occupation + \\
\hline & & & & Quality - Age - \\
\hline & & & & Quality - Language + \\
\hline & & & & Quality - Education + \\
\hline \multirow[t]{3}{*}{ (Fylkesnes et al., 2013); Zambia } & \multirow[t]{3}{*}{ Counsellor } & Home Based Testing and & Cluster randomised & Utilisation - Education + \\
\hline & & & $\mathrm{COI}$ & Utilisation - Gender + \\
\hline & & & & Utilisation - Age + \\
\hline (Hasegawa, Yasuoka, Ly, Nguon, & Village malaria & Child health programme & Cross-sectional study; & Utilisation - Place of residence + \\
\hline \& Jimba, 2013); Cambodia & & $\begin{array}{l}\text { providing malaria case } \\
\text { management and child health }\end{array}$ & High & (- those over 25 km away) \\
\hline & & services & & Utilisation - SES + \\
\hline & & & & Utilisation - Education + \\
\hline
\end{tabular}


Table 1 summarising country, type of CHW and service provided for included studies (Continued)

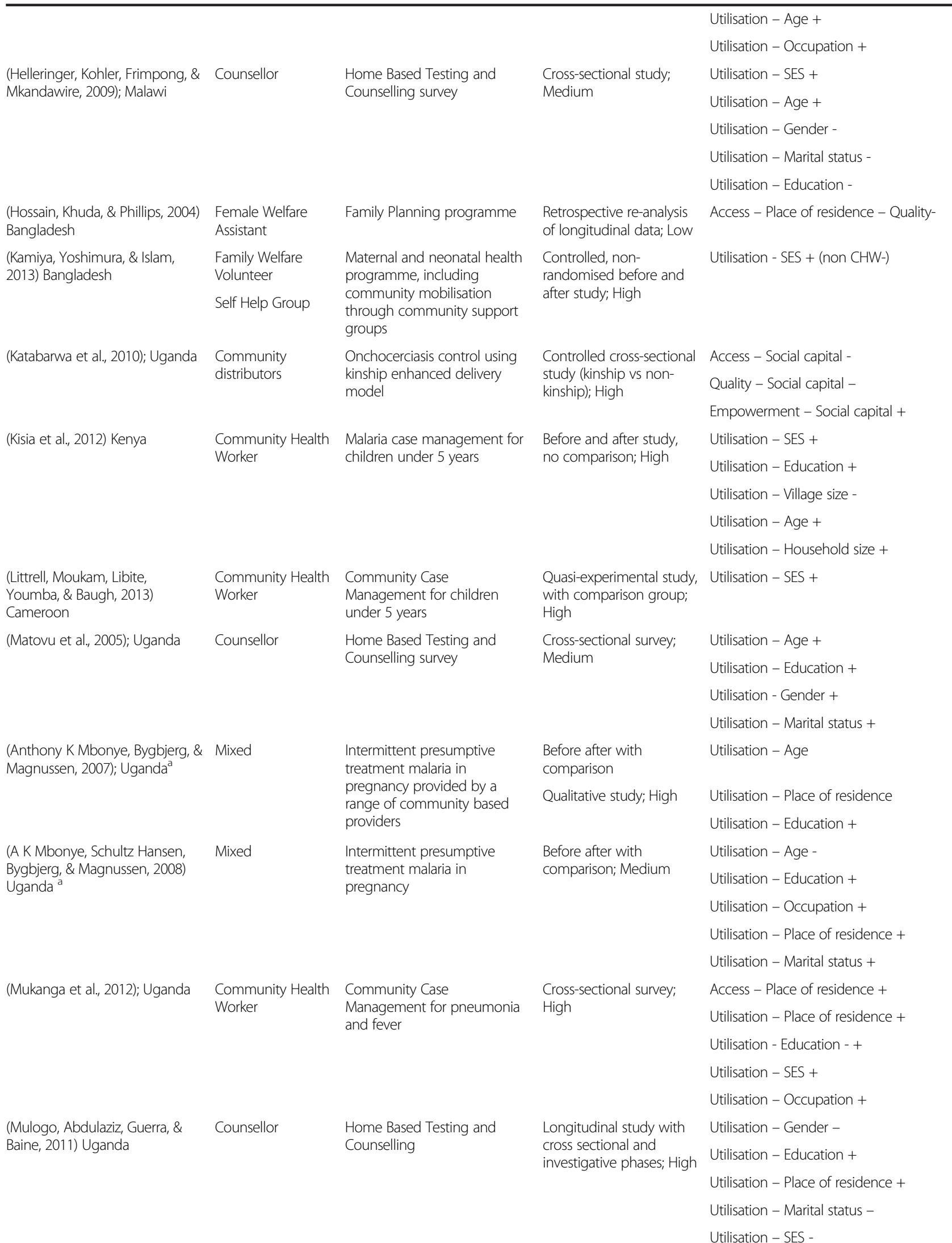


Table 1 summarising country, type of CHW and service provided for included studies (Continued)

\begin{tabular}{|c|c|c|c|c|}
\hline \multirow[t]{3}{*}{ (Mumtaz et al., 2013); Pakistan } & \multirow[t]{3}{*}{ Lady health worker } & \multirow{3}{*}{$\begin{array}{l}\text { Maternal and child health } \\
\text { programme providing door } \\
\text { step family planning, antenatal } \\
\text { and child health services }\end{array}$} & Cross-sectional study & Access - Social capital - \\
\hline & & & Qualitative study; High & Access - SES + \\
\hline & & & & Quality - Social capital - \\
\hline \multirow{4}{*}{$\begin{array}{l}\text { (Mutale, Michelo, Jürgensen, \& } \\
\text { Fylkesnes, 2010) Zambia }\end{array}$} & \multirow[t]{4}{*}{ Counsellor } & \multirow{4}{*}{$\begin{array}{l}\text { Home Based Testing and } \\
\text { Counselling }\end{array}$} & \multirow{4}{*}{$\begin{array}{l}\text { Cross-sectional study; } \\
\text { Medium }\end{array}$} & Utilisation - Place of residence + \\
\hline & & & & Utilisation - Gender + \\
\hline & & & & Utilisation - Education + \\
\hline & & & & Access - Age + \\
\hline \multirow{2}{*}{$\begin{array}{l}\text { (Naik, Tabana, Doherty, Zembe, } \\
\text { \& Jackson, 2012); South Africa }\end{array}$} & \multirow[t]{2}{*}{ Counsellor } & \multirow{2}{*}{$\begin{array}{l}\text { Home Based Testing and } \\
\text { Counselling }\end{array}$} & \multirow{2}{*}{$\begin{array}{l}\text { Cluster randomised trial } \\
\text { with comparison, } \\
\text { comparing home based } \\
\text { HTC with facility based; } \\
\text { High }\end{array}$} & Utilisation - Gender - \\
\hline & & & & Utilisation - Age + \\
\hline \multirow{3}{*}{$\begin{array}{l}\text { (Nsungwa-Sabiiti et al., 2007); } \\
\text { Uganda }\end{array}$} & \multirow[t]{3}{*}{ Drug distributor } & \multirow{3}{*}{$\begin{array}{l}\text { Malaria case management and } \\
\text { malaria counselling }\end{array}$} & \multirow{3}{*}{$\begin{array}{l}\text { Quasi-experimental } \\
\text { before after study with } \\
\text { comparison group; } \\
\text { Medium }\end{array}$} & Utilisation - SES - \\
\hline & & & & Utilisation -Gender + \\
\hline & & & & Utilisation - Education + \\
\hline \multirow{5}{*}{$\begin{array}{l}\text { (Onwujekwe, Ojukwu, Shu, \& } \\
\text { Uzochukwu, 2007) Nigeria }\end{array}$} & \multirow{5}{*}{$\begin{array}{l}\text { Community Health } \\
\text { Worker }\end{array}$} & \multirow[t]{5}{*}{ Malaria case management } & \multirow{5}{*}{$\begin{array}{l}\text { Before after study, no } \\
\text { comparison; Medium }\end{array}$} & Access - SES - \\
\hline & & & & Access - Number household residents - \\
\hline & & & & Access - Age - \\
\hline & & & & Utilisation - SES - \\
\hline & & & & Quality - SES - \\
\hline \multirow{4}{*}{$\begin{array}{l}\text { (Perry, King-Schultz, Aftab, \& Bry- } \\
\text { ant, 2007); Haiti }\end{array}$} & Animatrice & \multirow{4}{*}{$\begin{array}{l}\text { General health programme } \\
\text { involving household peer to } \\
\text { peer education }\end{array}$} & Cross-sectional study & \multirow[t]{4}{*}{ Access - Place of residence - } \\
\hline & Matrons & & Exit interview; Low & \\
\hline & Health Agents & & & \\
\hline & Monitrices & & & \\
\hline \multirow[t]{2}{*}{$\begin{array}{l}\text { (Quayyum et al., 2013); } \\
\text { Bangladesh }\end{array}$} & $\begin{array}{l}\text { Shasthaya Shebika } \\
\text { Shasthya Kormi }\end{array}$ & \multirow{2}{*}{$\begin{array}{l}\text { Maternal and neonatal health } \\
\text { programme providing } \\
\text { maternal health services and } \\
\text { education at home }\end{array}$} & \multirow{2}{*}{$\begin{array}{l}\text { Quasi-experimental, } \\
\text { before after study with } \\
\text { comparison area; High }\end{array}$} & \multirow[t]{2}{*}{ Utilisation - SES + (non CHW +/-) } \\
\hline & $\begin{array}{l}\text { Newborn Health } \\
\text { workers }\end{array}$ & & & \\
\hline \multirow{2}{*}{$\begin{array}{l}\text { (Quinley \& Govindasamy, 2007); } \\
\text { Nepal }\end{array}$} & Female & Child health (no details & Cross-sectional study & Utilisation - SES - \\
\hline & Volunteer & & $\begin{array}{l}\text { Demographic Health } \\
\text { Survey data); Low }\end{array}$ & Utilisation - Place of residence + \\
\hline (Siekmans et al., 2013); Kenya & Community Health & Malaria case management for & Before after study, no & Access - SES + \\
\hline & & under fives & comparison area; High & Utilisation - SES + \\
\hline & & & & Empowerment - SES + \\
\hline (D. O. Simba, 2005) Tanzania b & Community based & Family Planning provision of & Descriptive cross- & Utilisation - Age - \\
\hline & & $\begin{array}{l}\text { contraceptives and } \\
\text { information of sexual and }\end{array}$ & sectional stuay; Mleaium & Utilisation - Occupation + \\
\hline & & reproductive health & & Utilisation - Gender + \\
\hline & & & & Utilisation - Religion + \\
\hline & & & & Utilisation - SES + \\
\hline & & & & Quality - SES - \\
\hline & & & & Empowerment - SES + \\
\hline (D. Simba, Schuemer, Forrester, & Community Based & Family Planning provision of & Cross-sectional & Utilisation - Place of residence + \\
\hline d, $20 \mid 1$; i lanzanid & & $\begin{array}{l}\text { information of sexual and } \\
\text { reproductive health }\end{array}$ & aescripuve stuay; Low & Quality - SES + \\
\hline (Wolff et al., 2005) Uganda & Counsellor & $\begin{array}{l}\text { Home Based Testing and } \\
\text { Counselling }\end{array}$ & $\begin{array}{l}\text { Repeated cross-sectional } \\
\text { study }\end{array}$ & Utilisation - Age + \\
\hline & & & $\begin{array}{l}\text { Qualitative study; } \\
\text { Medium }\end{array}$ & Utilisation - Gender + \\
\hline
\end{tabular}


Table 1 summarising country, type of CHW and service provided for included studies (Continued)

\begin{tabular}{|c|c|c|c|c|}
\hline \multirow[t]{6}{*}{ (Wringe et al., 2008); Tanzania } & \multirow[t]{6}{*}{ Counsellor } & \multirow{6}{*}{$\begin{array}{l}\text { Voluntary Counselling and } \\
\text { Testing offered at purpose } \\
\text { built hut following household } \\
\text { questionnaire }\end{array}$} & \multirow{6}{*}{$\begin{array}{l}\text { Repeated cross-sectional } \\
\text { study; High }\end{array}$} & Utilisation - Gender - \\
\hline & & & & Utilisation - Education - \\
\hline & & & & Utilisation - Religion - \\
\hline & & & & Utilisation - Race - \\
\hline & & & & Utilisation - Place of residence - \\
\hline & & & & Utilisation - Age - \\
\hline
\end{tabular}

Note + pro equity, - anti equity, ? mixed equity findings

andicates two papers based on the same study

bindicates two papers based on the same study

reporting findings for quality. Studies mainly assessed quality in terms of satisfaction from the patient's perspective. Findings for quality tended to be negative, with no clear evidence for equitable quality of $\mathrm{CHW}$ services (Additional file 4: Table S5).

Findings from five studies (Additional file 4: Table S6) indicate that $\mathrm{CHW}$ programmes can generate some degree of community empowerment by utilising existing social capital and addressing knowledge gap according to socio-economic position.

What influences how equitable CHW programmes are in terms of access, utilisation, quality and community empowerment?

Our review identified that the same supply side and demand side barriers which limit equity of health services delivered from health facility can also influence the equity of CHW programmes if not adequately addressed during planning (see Table 2). This will be further expounded in addressing the second study question.

\section{Factors affecting accessibility}

Proximity of the service to the household is a vital factor in reducing inequities relating to place of residence [31]. However, when the $\mathrm{CHW}$ was not resident within the community [32] or intervention design did not vary the ratio of the number of households to the number of $\mathrm{CHWs}$ for different geographic areas (mountain versus plain), population dispersion [6] or intensity of tasks required of CHWs [33] inequities persisted with those living further from the $\mathrm{CHW}$ less likely to receive household visit [6, 33].

Pre-requisite educational requirements within certain $\mathrm{CHW}$ programmes $[32,34]$ resulted in more CHWs being recruited from and operating within communities with higher educational levels, thereby putting illiterate communities at a disadvantage.

Home visits by CHWs were more common among the most poor in three studies due to a range of reasons such as non-governmental organisation (NGO) facilitation with supervision and monitoring [5], recruitment of the most poor as CHWs [35] and deliberate targeting of most poor households for services by CHWs [36].
However, payments (for malaria treatment) remained a barrier to CHW service access for the most poor [37]. Recruitment of CHWs from areas outside their catchment community in Malawi was found to result in fewer household visits for the most poor as CHWs were less likely to reside in more remote areas [38].

Social capital (defined as the presence of an existing family, kin or social relationship with the $\mathrm{CHW}$ ) was influential in three studies with CHWs more likely to provide home visits or services to those with whom they have a kinship or a pre-established relationship [32, 35, 39]. This can have positive sequelae if the CHW is preferentially recruited from a poorer household, as was the case in Pakistan where the CHW role is considered low status and so attracts poorer women [35]. These findings are summarised in Additional file 4: Table S2.

\section{Factors affecting utilisation}

Findings for utilisation are divided into two main aspects: 1) Acceptance and use of community health services provided by $\mathrm{CHW}$ either within the home or at a local village health post (see Fig. 3) or 2) Uptake of referrals made by a $\mathrm{CHW}$ to services provided at a health facility (see Fig. 4).

\section{1) Acceptance and use of community health services}

Those living further from the health facility were found to be more likely to use CHW services in five studies where the intervention included home visits by $\mathrm{CHW}$ [40]; CHW provision of case management [31, 41]; contraception [42] or home based HIV testing and counselling (HTC) [43, 44]. However, poor supply chain and lack of $\mathrm{CHW}$ supplies was found to result in lower $\mathrm{CHW}$ utilisation rates for in one study for those living farthest (over $25 \mathrm{~km}$ ) from the health facility [41]. Meanwhile, geographic barriers continued to persist where clients had to travel to $\mathrm{CHW}$ home/health post in four studies with lower service utilisation for those living farthest from the CHW home/ health post $[31,32,45]$ and higher utilisation in a roadside community [46] and for the urban population compared with rural [47]. 
Table 2 indicating how CHW interventions can overcome supply and demand side barriers to equity

\begin{tabular}{ll}
\hline Barrier & How CHW intervention can overcome barrier \\
\hline Supply side (CHW services) & \\
Low number of health workers in & Local recruitment of CHWs, including recruitment of \\
hard-to-reach areas & CHWs from marginalised groups
\end{tabular}

Equity considerations for CHW programme planners

hard-to-reach areas

Time taken to reach service location

Provision of services within the client's home

Cost of services

Free service provision

Demand side (CHW services)

Demand for services and information about health care

Developing improved client knowledge about CHW role as health care providers through home visits, sensitisation meetings and community mobilisation

Waiting time for services, indirect costs (transport), opportunity costs

Provision of curative services and provision of HTC within the home

Education

Household expectations and community and cultural preferences

Reducing the knowledge/ behaviour gap between richest and poorest community members through one-to-one and group education

Provision of services within the home in cultural contexts where women are reluctant to seek care outside their home.

Demand side (Health facility services)

Demand for services and information about health care

Waiting time for services, indirect costs (transport), opportunity costs

Education

Household expectations and community and cultural preferences
CHW led demand creation strategies, community engagement and action planning

CHW training in problem solving

Use of a household risk assessment by $\mathrm{CHW}$ to ensure high risk households receive more frequent home visits to advise about for clinic attendance

Reimbursement for transportation

Community funds

Reducing the influence of education on health facility service utilisation among those with limited formal education through one-to-one and group education

CHW accompaniment during referrals
Ensure CHWs are recruited locally, not centrally

Consider options to include illiterate CHWs in areas where education levels are low

Ensure CHW selection reflects community - inclusion of CHWs from marginalised groups

CHW intervention planning to consider geographic features - reduced household numbers per CHW where households are far apart/ difficult terrain

Payment for services can continue to present a barrier to service use, even if CHW services are provided within the home

Consider comprehensive package of services, rather than single disease specific intervention

Weak sensitisation and community mobilisation around CHW intervention can lead to limited demand for services

Consider alternative approaches for certain groups e.g. HTC provision by a non-resident CHW for youth and work based HTC (rather than home based) for migrant men

Ensure strong supply chain for commodities to all CHWs

Need for supportive supervision

Need for strong referral links between community and health facility

Need to plan for behaviour change communication within CHW programme design

Need for consideration of existing social relationships between clients and $\mathrm{CHW}$

Consider the package of services provided at community level and whether this could reduce use of services by skilled provider at health facility (e.g. ANC)

Transport and opportunity costs will still exist, even where community is empowered and so community funds/ transport refunds are useful tools to overcome this barrier

Failure to develop community empowerment through support groups may hinder use of services at health facility level

Consider incentive for CHW to refer and accompany clients to health facility
Use of CHW services was demonstrated to reduce gender differences or to have no difference in utilisation rates between men and women in eight studies (four non- HTC studies and four home based HTC).
Provision of services by $\mathrm{CHWs}$ within the home in Pakistan helped to alleviate gender constraints which women face in using maternal child health services in a context where women's movements are restricted [34]. 


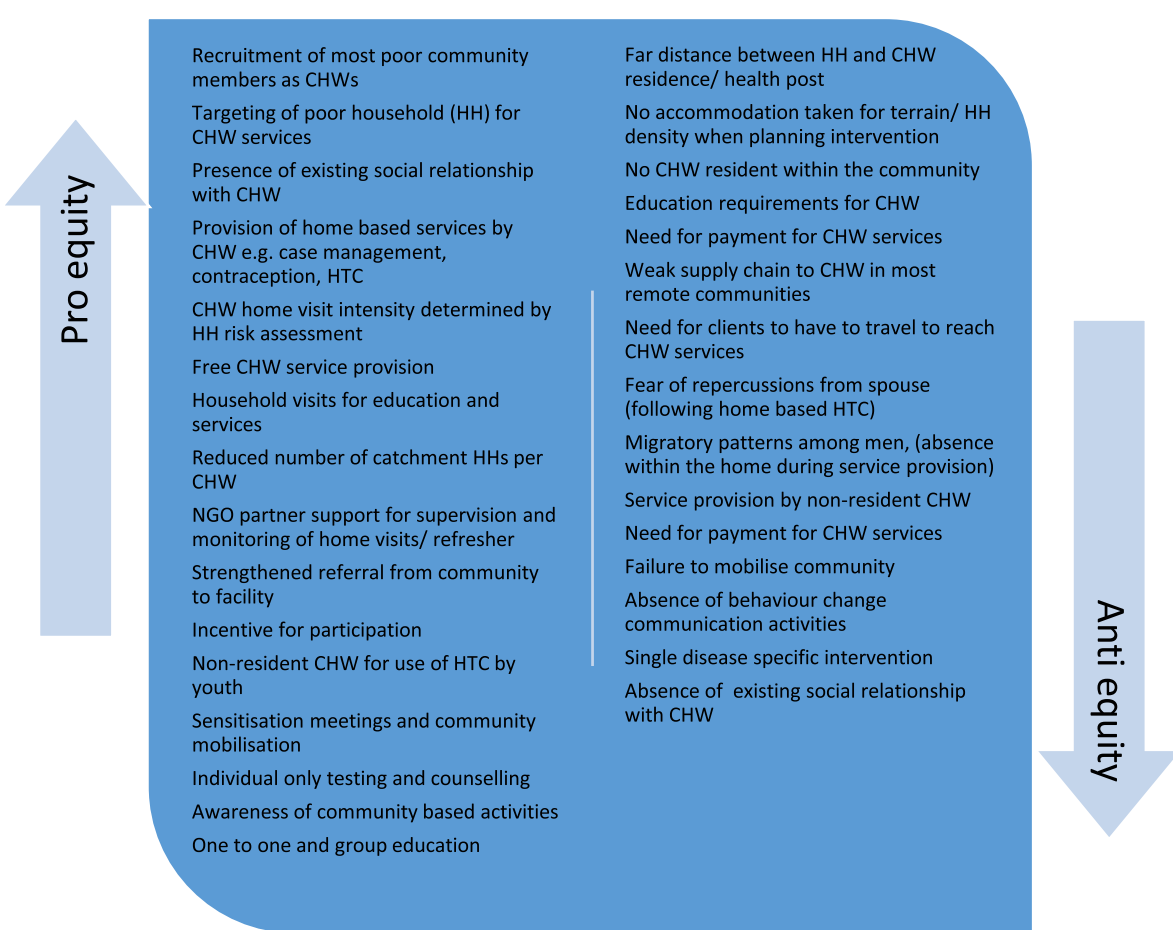

Fig. 3 Key CHW intervention features promoting or threatening equity of CHW service access, use, quality and community empowerment

However, gender inequities still persisted in five HTC studies, with fear of repercussions from spouses constraining women from disclosing sexually transmitted infection (STI) related symptoms during home based HTC compared with facility based [44] and higher utilisation of home based HTC among women in four studies, thought to be due to migratory patterns among men [48]. Where HTC was provided by CHW at clinic or purpose-built hut rather than being home based, utilisation was more common among men [46]. Women described difficulty finding time to leave the home and the need for standards of dress at health facility [49]. These gender inequities were virtually eliminated following home based delivery of HTC [49].

Utilisation was found to be higher among the least educated in three studies, influence of education was reduced following CHW provision of services within the home in four papers and no influence of education on CHW service utilisation in seven studies, although limited explanation was provided. However, where $\mathrm{CHW}$ services were provided by non-resident $\mathrm{CHW}$ [50] or at a purpose built hut [46] service utilisation remained lower among the least educated.

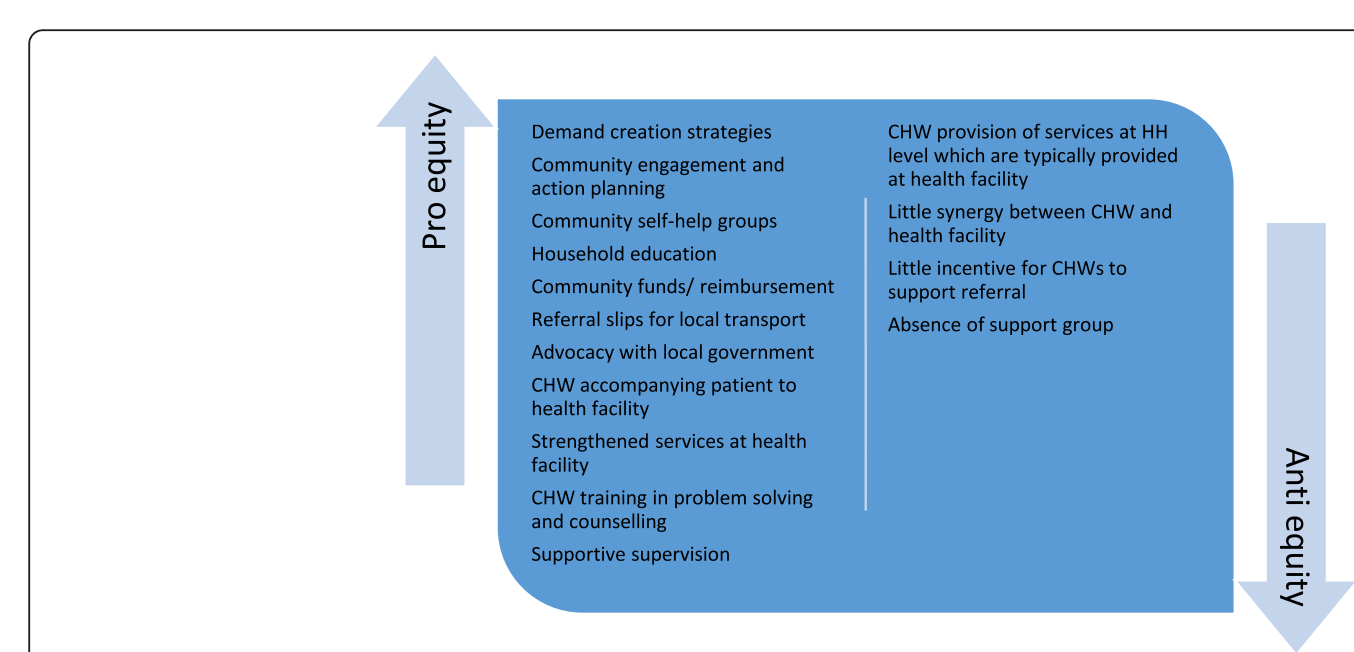

Fig. $4 \mathrm{CHW}$ intervention features promoting or threatening equitable uptake of $\mathrm{CHW}$ referral to health facility services 
CHWs strongly promoted more equitable utilisation of services according to socio-economic position (Additional file 4: Table S3), with nine papers reporting that utilisation of CHW services was more common among the poorest compared with the least poor within the population. Common features of $\mathrm{CHW}$ programmes which are utilised more by the poorest include free services; community based distribution of contraceptives; household visits for health education, HTC and curative services and community level case management. Other features of these CHW programmes include reduced number of catchment households for CHW [51]; NGO partner support through supervision and/ or refresher [36, 51-54]; strengthened referral from community to facility [51] and incentives for participation [50]. However, some inequities still persisted with three studies reporting that $\mathrm{CHW}$ service utilisation was less common among the poorest. Barriers to use of $\mathrm{CHW}$ services by the poorest included need for payment for malaria treatment in Nigeria [37] or free service delivery, but failure to mobilise mothers [55]; absence of behaviour change communication activities [55]; single disease specific (malaria) $\mathrm{CHW}$ intervention [37, 55].

Four studies described that provision of services by CHWs resulted in increased utilisation among previously underserved age groups, particularly HTC among youth. Features of these CHW programmes include non-resident $\mathrm{CHW}[43,47,50]$; sensitisation meetings or community mobilisation in advance $[47,50]$ and individual only HTC $[47,50]$. However, five studies reported no effect and two reported that use of $\mathrm{CHW}$ services was lower among selected age groups (youth) due to fear that home based HTC would prompt speculation from family members [49].

Utilisation of CHW services was also influenced by the presence of pre-existing social connections to CHW, religion, race, occupation and marital status. These findings are summarised in Additional file 4: Table S3.

\section{2) Uptake of referrals made by a CHW to services provided at a health facility.}

Socio-economic status was the leading influential stratifier for the uptake of referral (described in five studies). Increased utilisation of health facility services among the poor compared with the less poor in two studies $[51,56]$ included specific strategies to increase demand for services; community engagement through development of action plans involving both facility and community stakeholders; establishment of community support self-help groups to support women from low socio-economic position households; household education; community funds/ financial support/reimbursement; referral slips for local transport; advocacy for maternal health with local government; $\mathrm{CHW}$ accompanying patients to facility and strengthened services at facility level. However, use of CHW referral to health facility level services increased among the poor but still remained skewed in favour of the less poor in two studies [5, 38]. Common features of these studies included demand generation through home visits, training of CHWs in problem solving and counselling skills; supportive supervision; NGO support; CHW assessment and referral if danger signs present; establishment of demand generation groups. Use of health facility level services actually reduced among the poorest in one study due to the provision of antenatal care (ANC) by trained $\mathrm{CHW}$ at household level [51]. There was no improvement in uptake of facility level services in two studies due to little synergy between the $\mathrm{CHW}$ and the health facility, with little incentive for CHWs to support or facilitate referral to the health facility [34] or where there was no participant support group [56].

Level of risk influenced utilisation of health facility services in Guatemala, with higher use of health facility level services among households with higher risk and who spoke only one language. In this study the $\mathrm{CHW}$ carried out a household risk assessment, which identified households as high, medium or low risk and frequency of household visit varied accordingly, with households identified as high risk receiving most frequent $\mathrm{CHW}$ visits which encouraged use of services at health facility as needed. The study intervention also included support from supervision and referral team [45]. These findings are summarised in Additional file 4: Table S4.

\section{Factors affecting quality}

There were no studies that identified quality indicators. Perceived quality, using satisfaction with services as a proxy for quality was associated with awareness and practice of community based activities. Satisfaction was found to be higher in rural areas compared with urban [57] in one study in Brazil. The reason for higher satisfaction in rural areas was unclear but may relate to social, economic and cultural differences or differing expectations by populations. Two studies found lower quality for the poorest clients with lower reported satisfaction [58] and use of lower quality treatment by the poorest compared with the richest, where clients had to pay CHWs for malaria treatment [37]. Meanwhile having a pre-existing kinship relationship with the CHW resulted in greater satisfaction in two studies [35, 39]. These findings are summarised in Additional file 4: Table S5.

\section{Factors affecting community empowerment}

Studies mainly assessed community empowerment in terms of knowledge/behaviour change following $\mathrm{CHW}$ programme and indicate that $\mathrm{CHW}$ programmes can generate some degree of community empowerment by 
reducing the knowledge gap between richest and poorest in four studies which included a CHW role for health education via one-to-one and group education [58] and home visits [5, 38]. Meanwhile, community ownership was higher where a kinship relationship preexisted with the CHW. This was shown to result in greater community involvement in deciding the location of the treatment centre, CHW selection and mobilisation and more respondents having received health education in kinship enhanced compared with no preexisting kinship relationship with the CHW [39]. These findings are summarised in Additional file 4: Table S6.

\section{Discussion}

Our literature review adds to the evidence base for CHWs by providing the first review describing the extent of equity within different $\mathrm{CHW}$ programmes in different contexts and describing the features of $\mathrm{CHW}$ programmes which influence equity. The limited focus and evidence on equity that we found is in keeping with a recent review of maternal and child interventions on equity [30]. This highlights the evaporation of equity from policy (which often introduces $\mathrm{CHW}$ programmes as a means to promote both universal health coverage and equity [59]) to practice, where there is limited ongoing monitoring and evaluation of equity indicators within CHW programme design, in keeping with evidence for building equitable health systems [60]. This systematic review is therefore a timely review of current evidence, highlighting research gaps and priorities for future research.

\section{Supply and demand barriers and equity following introduction of CHW programmes}

This systematic review has found that CHWs are able to address both supply side barriers (aspects of health systems that hinder service uptake) and demand side barriers (factors influencing the ability to use health services at individual, household or community level [12]) to uptake of health services. However, it is important that policy makers consider design features which may hinder equity when planning programmes (see Table 2). These include supply side barriers such as low numbers of health workers (including CHWs), time to reach service, cost of services $[12,61]$ and demand side barriers to both CHW services and uptake of health facility services, such as demand for services and information about health care, waiting time, indirect and opportunity costs, education, household expectations, community and cultural preferences $[12,62]$.

\section{Quality and equity following introduction of $\mathrm{CHW}$ programmes}

This review has highlighted gaps in the extent to which quality is monitored with regards to equity stratifiers. Quality is widely identified as being a central tenet to equity $[2,4,63]$. It would therefore be expected that the quality of services provided by CHWs would be evaluated during studies which monitored equity. However, this review revealed quality was assessed in only five studies, four of which evaluated client satisfaction and one of which assessed use of more effective versus less effective anti-malarial treatment provided by CHW [37]. None of the included studies assessed the technical quality of services provided by the CHW according to any equity stratifier. This finding reveals a disparity between this review's findings and the literature on quality of care, which includes equity as one of the six dimensions of quality health care (effective, efficient, accessible, acceptable/ patient centred, equitable and safe) [64]. For CHW programmes to ensure quality equitable service provision for all groups it is vital that quality improvement (QI) approaches (which measure and understand performance gaps, before introducing, monitoring and evaluating interventions to close these gaps [65]) include an equity focus. Various tools for quality improvement have already been created, such as the CHW assessment and improvement matrix (CHW AIM) [66] and the authors would propose that equity be added as an additional programmatic component to this tool to ensure regular and consistent application of an equity lens during QI approaches for CHW programmes.

\section{Community empowerment and equity following introduction of $\mathrm{CHW}$ programmes}

It is commonly acknowledged that underlying social determinants must be addressed in order to tackle underlying causes of health inequities [2, 63]. CHWs are uniquely positioned as a link between the community and the health system. CHWs live within communities where they work and are able to observe these social determinants for health during household visits and day-to-day interactions with other members of their communities. However, while a recent literature review identified evidence for the empowerment of a $\mathrm{CHW}$ through his/her work, there was limited evidence described within the review regarding empowerment of the community through the CHW for implementation of lay health worker programmes [16]. Our systematic review found minimal literature which assesses the role of $\mathrm{CHWs}$ in tackling social determinants for health, which is in keeping with findings presented in Collaboration for Applied Health Research and Delivery (CAHRD) discussion paper during CAHRD consultation 2014 [67]. The role of CHWs as agents for change working within their communities to identify and address social determinants for health is a key and vital gap in the literature which the authors feel should be addressed through future implementation research. 


\section{Strengths and weaknesses of the data}

Given, the extent and volume of published literature about CHWs, there were limited studies which assessed the equity of these CHW programmes where a universal approach was adopted. Community health is being adopted widely as a means to promote and ensure universal health coverage and to build resilience $[7-9,68]$. It is therefore vital that adequate research assesses the equity of these services and identifies factors which influence provision of community health service delivery using a universal approach, in order to ensure community health services are planned and implemented in the most equitable manner. $\mathrm{CHW}$ intervention planning should take into account differences between contexts and measure service access, utilisation, quality and community empowerment for marginalised groups.

A notable omission is data relating to the equity of services for people with disabilities. Despite this being included within the search strategy, none of the studies included within this review provided evidence regarding the equity of services for people with disability as part of a CHW programme adopting a universal approach. There was also a lack of data regarding equity of services for older populations, as much of the age related data referred to youth (although age was not included as a specific search term). There is therefore an urgent need to better understand equity of $\mathrm{CHW}$ services for people with disabilities and older age groups.

\section{Study limitations}

We attempted to include a range of study designs in order to capture useful information and a range of search engines were used, including POPLINE, which sought to capture some unpublished studies. However, seven papers were identified from additional sources, rather than through the original search and so it is possible that some studies may not have been published which may have included relevant information. Due to the current emphasis of using CHW programmes as a means of increasing universal health coverage, we determined to include studies which adopted a universal approach, in order to elucidate findings applicable for CHW programmes applied to whole populations. However, there were a number of studies which were excluded based on having adopted a targeted approach rather than universal, as it is difficult to truly assess equity using targeted studies, but they may have had included valuable lessons.

Assessment of quality was conducted to provide greater understanding for the reader of the quality of data included within the review, but was not used to 'weigh' synthesis of evidence for included studies.

\section{Conclusion}

We found that CHW programmes across diverse contexts promote more equitable access and use of $\mathrm{CHW}$ services at household level and have the potential to contribute towards improved uptake of referral for health facility services. However, care must be taken by policymakers and implementers to take into account $\mathrm{CHW}$ programme features which can influence the equity of services provided during planning and implementation of $\mathrm{CHW}$ programmes. The quality of $\mathrm{CHW}$ services for differing socio-demographic groups and the role of CHWs in empowering communities to address underlying social determinants for change are key gaps in the current $\mathrm{CHW}$ evidence base. It is vital that equity indicators are included within routine $\mathrm{CHW}$ monitoring and that equity is incorporated within quality improvement approaches for community health to ensure that the pro-equity statements in $\mathrm{CHW}$ policies do not evaporate in practice. We recommend that evidence based decision-making by policymakers take into consideration the underlying programme features which influence the equity of $\mathrm{CHW}$ interventions in addition to performance (motivation and competencies); effectiveness and cost-effectiveness.

\section{Ethics approval and consent to participate}

Since it is a review paper, the study did not need ethical committee approval.

\section{Consent for publication}

Not applicable as manuscript does not contain any individual persons data.

\section{Availability of data and materials}

Protocol for this review was registered with PROSPERO and is available at http://www.crd.york.ac.uk/PROSPERO/ DisplayPDF.php?ID=CRD42014013067.

References for included papers are included within list of references.

\section{Endnotes}

${ }^{1}$ PROGRESS plus is an acronym referring to: place of residence; race; occupation; gender; religion; education; socioeconomic position; social capital; plus - disability; age; sexual orientation.

${ }^{2}$ Identified papers which included findings for additional stratifiers were analysed for all PROGRESS plus equity stratifiers.

${ }^{3} \mathrm{CHW}$ inclusion and exclusion criteria are identified in Additional file 1.

${ }^{4}$ Given that the purpose of the review is to identify lessons for policymakers implementing universal $\mathrm{CHW}$ programs, it is difficult to truly assess equity through a targeted study and so only studies with a universal approach were included. 


\section{Additional files}

Additional file 1: Equity and community health workers search strategy. (DOCX $28 \mathrm{~kb}$ )

Additional file 2: Coding Framework. (DOCX $11 \mathrm{~kb}$ )

Additional file 3: Modified Critical Appraisal Skills Programme (CASP). Table S1A Modified CASP Checklist. Table S1B Example completion of Modified CASP checklist. (DOCX 14 kb)

Additional file 4: Table S2. Summarising equity findings for access of CHW services. Table S3 Summarising utilisation of CHW services at household or health post and equity. Table S4 summarising uptake of referral by CHW for health facility services. Table S5 Summarising quality of CHW services and equity. Table $\mathrm{S} 6$ summarising community empowerment. (DOCX 107 kb)

\section{Abbreviations}

CASP: Critical Appraisal Skills Programme; CHW: Community Health Worker; CTC: Close-To-Community; HTC: HIV Testing and Counselling; IPTp: Intermittent preventive treatment in pregnancy; NGO: Non Governmental Organization; PROGRESS: Place of residence, race, occupation, gender, religion, education, socioeconomic status, social capital; SES: Socio Economic Status; UHC: Universal Health Coverage; WHO: World Health Organization.

\section{Competing interests}

The authors declare that they have no competing interests.

\section{Authors' contributions}

RM and MT conceived of the study and participated in it's design and protocol development. RM carried out review of titles and abstracts to assess eligibility, assessed full texts against inclusion criteria, conducted data extraction, quality assessment, analysis and drafted manuscript. WG double read and assessed al full texts selected for inclusion plus $10 \%$ of remaining full text articles, double read all data extraction and assessed quality. MT triple read full text papers where RM and WG disagreed. ST and MT critically reviewed and input to the manuscript. All authors have read and approved the final manuscript.

\section{Acknowledgements}

Special thanks to Dr Maryse Kok, Professor Paul Garner and Dr Claire Glenton for insights regarding development of research protocol and to Dr Vittoria Lutje and Martin Chapman for assistance with development of search strategy.

\section{Funding}

The research leading to these results was conducted in collaboration with the REACHOUT consortium and has received co-funding from the European Union Seventh Framework Programme ([FP7/2007-2013] [FP7/2007-2011]) under grant agreement number 306090. REACHOUT is an ambitious 5-year international research consortium aiming to generate knowledge to strengthen the performance of CHWs and other close-to-community providers in promotional, preventive and curative primary health services in lowand middle-income countries in rural and urban areas in Africa and Asia.

\section{Received: 22 September 2015 Accepted: 21 April 2016}

Published online: 20 May 2016

\section{References}

1. Chopra M, Sharkey A, Dalmiya N, Anthony D, Binkin N. Strategies to improve health coverage and narrow the equity gap in child survival, health, and nutrition. Lancet. 2012;380(9850):1331-40

2. World Health Organisation, Health, and Commission on Social Determinants of Health, "Closing the gap in a generation," 2008. [Online]. Available: http:// www.who.int/social_determinants/final_report/csdh_finalreport_2008.pdf. [Accessed: 04-Apr-2014]

3. Boerma JT, Bryce J, Kinfu Y, Axelson H, Victora CG. Mind the gap: equity and trends in coverage of maternal, newborn, and child health services in 54 Countdown countries. Lancet. 2008;371(9620):1259-67.

4. Whitehead $\mathrm{M}$. The concepts and principles of equity and health Copenhagen: World Health Organization; 1990.

5. Baqui AH, Rosecrans AM, Williams EK, Agrawal PK, Ahmed S, Darmstadt GL, Kumar V, Kiran U, Panwar D, Ahuja RC, Srivastava VK, Black RE, Santosham M.
NGO facilitation of a government community-based maternal and neonatal health programme in rural India: improvements in equity. Health Policy Plan. 2008;23(4):234-43.

6. Perry HB, King-Schultz LW, Aftab AS, Bryant JH. Health equity issues at the local level: socio-geography, access, and health outcomes in the service area of the Hôpital Albert Schweitzer-Haiti. Int J Equity Health. 2007;6:7.

7. Global Health Workforce Alliance. "Synthesis Paper: Developed out of the outcomes of four consultations on Community Health Workers and other Frontline Health Workers held in May/ June 2012". 2012. p. 1-27.

8. The Earth Institute Columbia University, "One Million Community Health Workers: Technical Task Force Report," 2013. [Online]. Available: http:// 1 millionhealthworkers.org/files/2013/01/1 mCHW_TechnicalTaskForceReport. pdf. [Accessed: 04-Apr-2014].

9. Naimoli JF, Frymus DE, Quain EE, Roseman EL. "Community and Formal Health System Support for Enhanced Community Health Worker Performance: A U.S. Government Evidence Summit," Bethesda, MD: USAID; 2012.

10. Carrera C, Azrack A, Begkoyian G, Pfaffmann J, Ribaira E, O'Connell T, Doughty P, Aung KM, Prieto L, Rasanathan K, Sharkey A, Chopra M, Knippenberg R. The comparative cost-effectiveness of an equity-focused approach to child survival, health, and nutrition: a modelling approach. Lancet. 2013;380(9850):1341-51.

11. Kok MC, Dieleman M, Taegtmeyer M, Broerse JE, Kane SS, Ormel H, Tijm MM, de Koning KA. "Which intervention design factors influence performance of community health workers in low- and middle-income countries? A systematic review," Health Policy Plan. 2014. p. 1-21.

12. Jacobs B, Ir P, Bigdeli M, Annear PL, Van Damme W. "Addressing access barriers to health services: An analytical framework for selecting appropriate interventions in low-income Asian countries". Health Policy Plan. 2012;27:288-300

13. Lewin S, Munabi-Babigumira S, Glenton C, Daniels K, Bosch-Capblanch X, Van Wyk BE, Odgaard-Jensen J, Johansen M, Aja GN, Zwarenstein M, Scheel IB. "Lay health workers in primary and community health care for maternal and child health and the management of infectious diseases". Cochrane database Syst Rev Online. 2010;3(3):CD004015.

14. Victora CG, Vaughan JP, Barros FC, Silva AC, Tomasi E. Public health Explaining trends in inequities : evidence from Brazilian child health studies. Lancet. 2000;356:1093-8.

15. Barros AJD, Ronsmans C, Axelson H, Loaiza E, Bertoldi AD, França GVa, Bryce J, Boerma JT, Victora CG. "Equity in maternal, newborn, and child health interventions in Countdown to 2015: a retrospective review of survey data from 54 countries". Lancet. 2012;379(9822):1225-33.

16. Glenton C, Colvin CJ, Carlsen B, Swartz A, Lewin S, Noyes J, Rashidian A. "Barriers and facilitators to the implementation of lay health worker programmes to improve access to maternal and child health: qualitative evidence synthesis". Cochrane Database Syst Rev. 2013;10(10):CD010414-2013

17. Kok MC, Kane SS, Tulloch O, Ormel H, Theobald S, Dieleman M, Taegtmeyer $\mathrm{M}$, Broerse JE, de Koning KA. "How does context influence performance of community health workers in low- and middle-income countries? Evidence from the literature," Heal Res Policy Syst. 2015;13:1-14.

18. Welch V, Petticrew M, Tugwell P, Moher D, O'Neill J, Waters E, White H. "PRISMA-Equity 2012 extension: reporting guidelines for systematic reviews with a focus on health equity". PLoS Med. 2012:9(10):e1001333.

19. Kok M, De Koning K, Ormel H, Kane S. "Reachout International Literature Review." Amsterdam: USAID; 2013.

20. Van Olmen J, Criel B, Van Damme W, Marchal B, Hoeree T, Pirard M, Kegels G. Studies in Health Services Organisation and policy: Analysing health systems to make them stronger, vol. 16. Antwerp: ITG Press; 2011. p. 93.

21. Pelcastre-Villafuerte B, Ruiz M, Meneses S, Amaya C, Márquez M, Taboada A, Careaga K. "Community-based health care for indigenous women in Mexico: a qualitative evaluation". Int J Equity Health. 2014;13(1):2-2014.

22. SDG open Working Group. "Sustainable Development Goals Open Working Group proposal for Open Working Group proposal for Sustainable Development Goals". 2015

23. Tanahashi T. Health service coverage and its evaluation. Bull World Health Organ. 1978:56(2):295-303.

24. O'Neill J, Tabish H, Welch V, Petticrew M, Pottie K, Clarke M, Evans T, Pardo Pardo J, Waters E, White H, Tugwell P. Applying an equity lens to interventions: using PROGRESS ensures consideration of socially stratifying factors to illuminate inequities in health. J Clin Epidemiol. 2014;67(1):56-64 
25. McCollum R, Otiso L, Mireku M, Theobald S, de Koning K, Hussein S, Taegtmeyer M. "Exploring perceptions of community health policy in Kenya and identifying implications for policy change," Health Policy Plan. 2015;0(0): 1-11.

26. McCollum R, Taegtmeyer, Mchenge M. "Review of the equity of services provided by community health workers," PROSPERO International prospective register of systematic reviews, 2014. [Online]. Available: http://www.crd.york.ac.uk/PROSPERO/DisplayPDF.php?ID=CRD42014013067. [Accessed: 18-Sep-2015].

27. Tugwell P, Petticrew M, Kristjansson E, Welch V, Ueffing E, Waters E, et al. Assessing equity in systematic reviews: realising the recommendations of the Commission on Social Determinants of Health. BMJ. 2010;341:c4739.

28. National Collaborating Centre for Determinants of Health. "Let's talk universal and targeted approaches to health equity". 2013.

29. Critical Appraisal Skills Programme, "Critical Appraisal SKills Programme (CASP) Qualitative Research Checklist," 2013. [Online]. Available: http:// media.wix.com/ugd/dded87_951541699e9edc71ce66c9bac4734c69.pdf. [Accessed: 06-May-2015].

30. Yuan B, Målqvist M, Trygg N, Qian X, Ng N, Thomsen S. What interventions are effective on reducing inequalities in maternal and child health in low- and middle-income settings? A systematic review. BMC Public Health. 2014;14:634.

31. Mukanga D, Tibenderana JK, Peterson S, Pariyo GW, Kiguli J, Waiswa P, Babirye R, Ojiambo G, Kasasa S, Pagnoni F, Kallander K. "Access, acceptability and utilization of community health workers using diagnostics for case management of fever in Ugandan children : a crosssectional study," Malaria Journal. 2012;11(121):1-10.

32. Bell D, Go R, Miguel C, Parks W, Bryan J. "Unequal tratment access and malaria risk in a community-based intervention program in the Philippines," Southeast Asian J Trop Med Public Health. 2005;36(3):1-4.

33. Hossain MB, Khuda B-E, Phillips JF. The effects of outreach on perceived quality of care in two rural areas of Bangladesh. J Biosoc Sci. 2004;36(5):507-22.

34. DasGupta M, Mansuri G, Nistha S, Vishwanath T. "Overcoming Gender-based Constraints to Utilization of Maternal and Child Health Services in Pakistan : The Role of the Doorstep Delivery System". 2007.

35. Mumtaz Z, Salway S, Nykiforuk C, Bhatti A, Ataullahjan A, Ayyalasomayajula B. The role of social geography on Lady Health Workers' mobility and effectiveness in Pakistan. Soc Sci Med. 2013;91:48-57.

36. Siekmans K, Sohani S, Kisia J, Kiilu K, Wamalwa E, Nelima F, Otieno DO, Nyandigisi A, Akhwale W, Ngindu A. Community case management of malaria: a pro-poor intervention in rural Kenya. Int Health. 2013;5(3):196-204

37. Onwujekwe O, Ojukwu J, Shu E, Uzochukwu B. Inequities in valuation of benefits, choice of drugs, and mode of payment for malaria treatment services provided by community health workers in Nigeria. Am J Trop Med Hyg. 2007;77(1):16-21.

38. Callaghan-Koru J a, Nonyane BA, Guenther T, Sitrin D, Ligowe R, Chimbalanga E, Zimba E, Kachale F, Shah R, Baqui AH. "Contribution of community-based newborn health promotion to reducing inequities in healthy newborn care practices and knowledge: evidence of improvement from a three-district pilot program in Malawi". BMC Public Health. 2013; 13(1):1052.

39. Katabarwa MN, Habomugisha P, Agunyo S, McKelvey AC, Ogweng N, Kwebiiha S, Byenume F, Male B, McFarland D. Traditional kinship system enhanced classic community-directed treatment with ivermectin (CDTI) for onchocerciasis control in Uganda. Trans R Soc Trop Med Hyg. 2010; 104(4):265-72

40. Mbonye AK, Schultz Hansen K, Bygbjerg IC, Magnussen P. Effect of a community-based delivery of intermittent preventive treatment of malaria in pregnancy on treatment seeking for malaria at health units in Uganda. Public Health. 2008;122(5):516-25.

41. Hasegawa A, Yasuoka J, Ly P, Nguon C, Jimba M. "Integrating child health services into malaria control services of village malaria workers in remote Cambodia: service utilization and knowledge of malaria management of caregivers". Malar J. 2013;12(1):292.

42. Simba D, Schuemer C, Forrester K, Hiza M. "Reaching the poor through community-based distributors of contraceptives: experiences from Muheza district, Tanzania," Tanzania Journal of Health Research. 2011; 13(1):1-10.

43. Mutale W, Michelo C, Jürgensen M, Fylkesnes K. Home-based voluntary HIV counselling and testing found highly acceptable and to reduce inequalities. BMC Public Health. 2010;10:347.
44. Mulogo EM, Abdulaziz AS, Guerra R, Baine SO. "Facility and home based HIV Counseling and Testing: a comparative analysis of uptake of services by rural communities in southwestern Uganda". BMC Health Serv Res. 2011;11(1):54

45. Fort MP, Grembowski D, Heagerty P, Lim SS, Mercer MA. Evaluation of a demonstration primary health care project in rural Guatemala: the influence of predisposing, enabling and need factors on immunization coverage, equitable use of health care services and application of treatment guidelines. Int Health. 2012;4(3):220-8.

46. Wringe A, Isingo R, Urassa M, Maiseli G, Manyalla R, Changalucha J, Mngara J, Kalluvya S, Zaba B. Uptake of HIV voluntary counselling and testing services in rural Tanzania: implications for effective HIV prevention and equitable access to treatment. Trop Med Int Health. 2008;13(3):319-27.

47. Dalal W, Feikin DR, Amolloh M, Ransom R, Burke H, Lugalia F, Ouma A, Laserson KF, Mermin J, Breiman RF, Bunnell R. Home-based HIV testing and counseling in Rural and Urban Kenyan Communities. J Acquir Immune Defic Syndr. 2013;62(2):47-54.

48. Naik R, Tabana H, Doherty T, Zembe W, Jackson D. "Client characteristics and acceptability of a home-based HIV counselling and testing intervention in rural South Africa". BMC Public Health. 2012;12(1):824.

49. Wolff B, Nyanzi B, Katongole G, Ssesanga D, Ruberantwari A, Whitworth J. Evaluation of a home-based voluntary counselling and testing intervention in rural Uganda. Health Policy Plan. 2005;20(2):109-16.

50. Helleringer $\mathrm{S}$, Kohler $\mathrm{H}$, Frimpong JA, Mkandawire J. Increasing uptake of HIV testing and counseling among the poorest in Sub-Saharan Countries. Epidemiol Soc Sci. 2009;51(2):185-93.

51. Quayyum Z, Khan MNU, Quayyum T, Nasreen HE, Chowdhury M, Ensor T. "'Can community level interventions have an impact on equity and utilization of maternal health care' - Evidence from rural Bangladesh," Int J Equity Health. 2013;12(1):1-14.

52. Baqui AH, Arifeen SE, Williams EK, Ahmed S, Mannan I, Rahman SM, Begum N, Seraji HR, Winch PJ, Santosham M, Black RE, Darmstadt GL. Effectiveness of home-based management of newborn infections by community health workers in rural Bangladesh. Pediatr Infect Dis J. 2009;28(4):304-10.

53. Kisia J, Nelima F, Otieno DO, Kiilu K, Emmanuel W, Sohani S, Siekmans K, Nyandigisi A, Akhwale W. "Factors associated with utilization of community health workers in improving access to malaria treatment among children in Kenya". Malar J. 2012;11(1):248.

54. Littrell M, Moukam LV, Libite R, Youmba JC, Baugh G. Narrowing the treatment gap with equitable access: mid-term outcomes of a community case management program in Cameroon. Health Policy Plan. 2013;28(7):705-16

55. Nsungwa-Sabiiti J, Peterson S, Pariyo G, Ogwal-Okeng J, Petzold MG, Tomson G. Home-based management of fever and malaria treatment practices in Uganda. Trans R Soc Trop Med Hyg. 2007;101(12):1199-207.

56. Kamiya Y, Yoshimura Y, Islam MT. An impact evaluation of the Safe Motherhood Promotion Project in Bangladesh: Evidence from Japanese aidfunded technical cooperation. Soc Sci Med. 2013;83:34-41.

57. Atkinson S, Haran D. Individual and district scale determinants of users' satisfaction with primary health care in developing countries. Soc Sci Med. 2005;60(3):501-13.

58. Simba DO. "CBD research in Muheza district: Final report for the Tanzanian German Programme to Support Health (TGPSH)/ GTZ". 2005.

59. Tulenko K, Møgedal S, Afzal MM, Frymus D, Oshin A, Pate M, Quain E, Pinel A, Wynd S, Zodpey S. Community health workers for universal health-care coverage: from fragmentation to synergy. Bull World Health Organ. 2013; 91(11):847-52.

60. Theobald S, Taegtmeyer M, Squire SB, Crichton J, Simwaka BN, Thomson R, Makwiza I, Tolhurst R, Martineau T, Bates I. Towards building equitable health systems in Sub-Saharan Africa: lessons from case studies on operational research. Health Res Policy Syst. 2009;7:26.

61. Chopra M. "Addressing health systems strengthening through an health equity lens". BMC Health Serv Res. 2013;13 Suppl 2:S13.

62. Ensor TIM, Cooper S. Overcoming barriers to health service access influencing the demand side. Health Policy Plan. 2004;19:69-79.

63. Solar O, Irwin A. "COMMISSION ON SOCIAL DETERMINANTS OF HEALTH A Conceptual Framework for Action on the Social Determinants of Health". 2007.

64. World Health Organisation, "Quality of care: A process for making strategic choices in health systems," Geneva: USAID; 2006.

65. Tawfik Y, Segall M, Necochea $E_{1}$ Jacobs T. "Finding Common Ground: Harmonizing the Application of Different Quality Improvement Models in 
Maternal, Newborn, and Child Health Programs," Bethesda, MD: USAID; 2010.

66. Crigler L, Hill K, Furth R, Bjerregaard D. "Community Health Worker Assessment and Improvement Matrix (CHW AIM): A Toolkit for Improving CHW Programs and Services Community Health Worker Assessment and Improvement Matrix (CHW AIM):" Bethesda, MD: USAID; 2011.

67. Theobald S, MacPherson E, McCollum R, Tolhurst R. "Close to community health providers post 2015: Realising their role in responsive health systems and addressing gendered social determinants of health". BMC Proc. 2015;9 Suppl 10:S8.

68. MDG health envoy. "Strengthening Primary Health Care through Community Health Workers: Investment Case and Financing Recommendations". 2015.

69. Rifkin SB. A framework linking community empowerment and health equity: it is a matter of CHOICE. J Heal Popul Nutr. 2003;21(3):168-80.

Submit your next manuscript to BioMed Central and we will help you at every step:

- We accept pre-submission inquiries

- Our selector tool helps you to find the most relevant journal

- We provide round the clock customer support

- Convenient online submission

- Thorough peer review

- Inclusion in PubMed and all major indexing services

- Maximum visibility for your research

Submit your manuscript at www.biomedcentral.com/submit
Biomed Central 